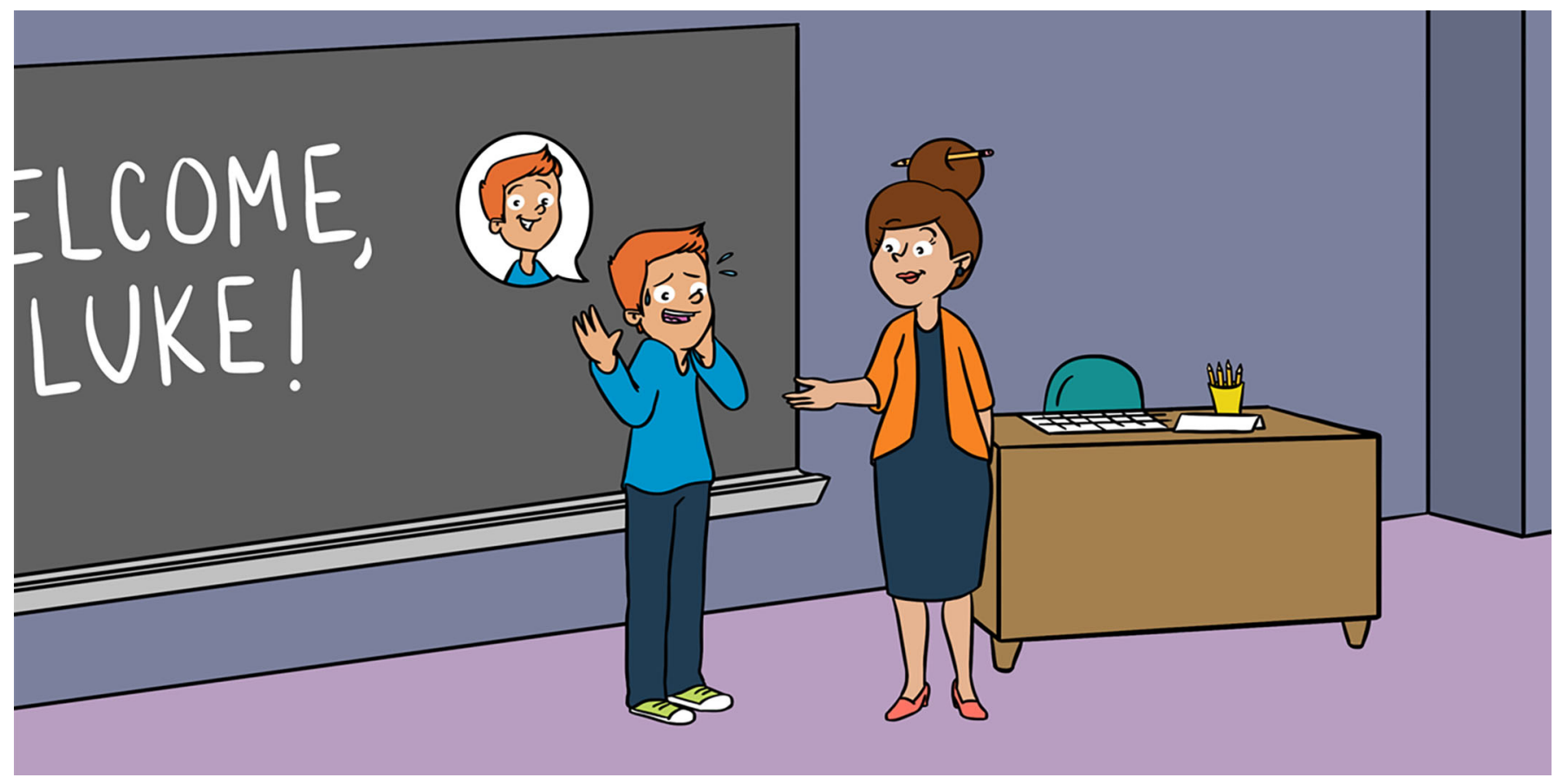

\title{
WHO DOES YOUR BRAIN THINK YOU ARE? THE SCIENCE OF THINKING ABOUT YOURSELF
}

Nathan A. Jorgensen * and Eva H. Telzer

Department of Psychology and Neuroscience, University of North Carolina at Chapel Hill, Chapel Hill, NC, United States

YOUNG REVIEWER:

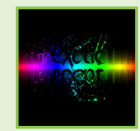

BEN

AGE: 13
Psychologists have been studying self-perceptions (how we think about ourselves) for a long time. They have learned that as kids transition into the teenage years, their self-perceptions become more social, meaning they start to think more about other people. Recently, neuroscientists have been studying what is going on in our brains when we think about ourselves, which has helped us understand some of the reasons why self-perceptions become more social. Around the time that kids start going through puberty, the medial prefrontal cortex (mPFC), a part of the "social brain," starts working a lot harder when they think about themselves. This means that the same part of the brain that thinks about others is also used to think about ourselves! Neuroscience has helped us understand that changes in the body and brain can explain some of the reasons why our self-perceptions become more social as we grow!

Imagine your family just moved to a new town. You probably have a flood of feelings going through your head-sadness, curiosity, excitement, and probably some nervousness, too! It is your first day 
SELF-PERCEPTIONS

How people think about themselves at your new school-you see new faces, hear new voices, and hope that you will be able to meet a new friend. As class starts, your teacher brings you to the front, tells everyone your name, and says to you, "Tell us a little bit about yourself!"

Woah-you were not ready for that! You pause for a moment to think, and then what do you say? If you have ever had to tell people about yourself, what sorts of things did you talk about? What things are you thinking about right now as you read this article? Well, psychologists (scientists who study people) have been studying this for a long time and have learned some really interesting things about self-perceptions (how we think about ourselves). And, more recently, scientists have even started studying what goes on inside your brain when you think about yourself! In this article, we are first going to tell you about how our self-perceptions change as we grow up, and then show you how neuroscience helps us understand why they change.

\section{HOW DOES THE WAY WE THINK ABOUT OURSELVES CHANGE OVER TIME?}

When they are born, little babies do not know very much about themselves. But as they grow and interact with people and things, they learn more about themselves, such as basic information (their name and age), what they like (favorite color, for example), and what they are good at (maybe being a fast runner) [1]. Self-perceptions become more complex throughout childhood, but some of the biggest changes start to happen around the time kids hit puberty, which usually happens sometime between ages 8 and 11. During puberty, the body and brain go through a lot of changes. Self-perceptions become more social, meaning that thinking about ourselves is not just thinking about ourselves anymore, but we start to think about others at the same time. For example, rather than thinking "I am good at math," we might compare ourselves to someone else by saying "I am better than my sister at math." Or we might go from asking ourselves, "Do I like the way I look?" to "Do other people like the way I look?" So, as your brain grows, your self-perceptions start to include other people, too.

\section{WHAT CAN NEUROSCIENCE TEACH US ABOUT SELF-PERCEPTIONS?}

You live in a really remarkable time of advanced science-many people would not have been able to read an article like this when they were your age, because scientists did not have the technology to study people's brains yet! It was not until the late 1990s and early 2000s that we have been able to learn about what the brain is doing when we think about ourselves. To do this, scientists take pictures of the brain using something called functional magnetic resonance imaging 
Figure 1

(A) A scientist helping someone get ready to go into the MRI scanner to take pictures of their brain. (B) What MRI pictures of the brain look like from the side and front of the head.

\section{FUNCTIONAL}

MAGNETIC

RESONANCE

IMAGING (fMRI)

Using a strong magnet to safely take pictures of activity in the brain.

\section{MEDIAL}

PREFRONTAL CORTEX (MPFC)

An important part of the "social brain" toward the front of the brain (behind the forehead) that is active when people think about others. It has also helped us understand how self-perceptions become more social over time, because for adolescents, the MPFC is also active when thinking about the self.

\section{ADOLESCENCE}

The period of time between childhood and adulthood, which starts when puberty begins. Because the exact timing of puberty is different for everyone, adolescence is often used to mean the teenage years.

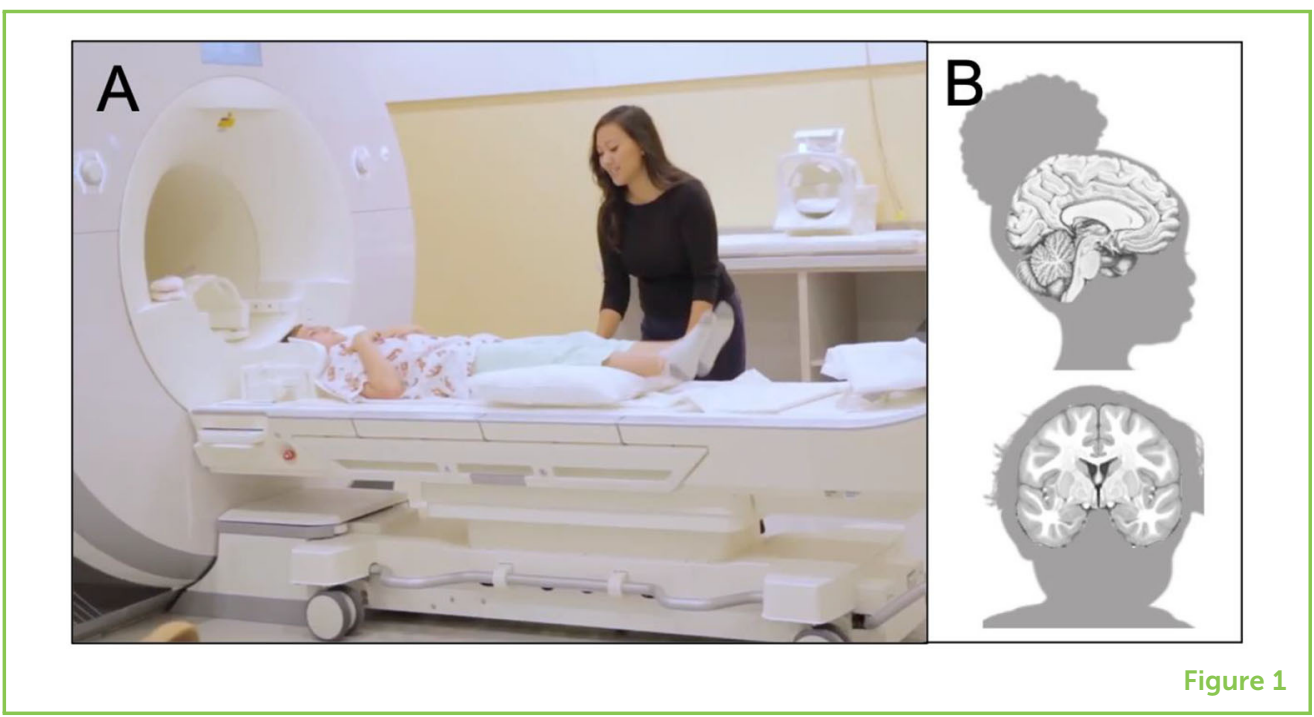

(fMRI). When you are in the fMRI scanner (Figure 1), scientists use a giant magnet to see how blood is moving around in your brain (see [2] if you want to learn more about MRI). This allows scientists to see which areas of the brain are active when children do different things, like reading, looking at pictures, or thinking about themselves. If more blood goes to some parts of your brain right after you do one of these things, this tells scientists that those parts of your brain were more active while you were doing the task.

So, what have scientists learned by using fMRI to study self-perceptions? This research has focused on two main questions about the brain and the self: (1) What parts of the brain are most active when we think about ourselves? (2) Are the brain regions that think about the self different for kids, teens, and adults? Scientists have discovered that there is one main part of the brain that becomes more active when people think about themselves: the medial prefrontal cortex (mPFC) [3-5]. The $\mathrm{mPFC}$ is toward the front of the brain, just behind the forehead (Figure 2) and is a part of what scientists call the "social brain." The social brain is activated when we think about other people. So, it is very interesting that the same brain region we use to think about other people is activated when we think about ourselves-but this is not the case for all ages; it starts in the teenage years (also known as adolescence).

As we have already mentioned, our self-perceptions get more complex as we get older. In childhood, we tend to think rather simply about things like hobbies or basic traits. We certainly still think about these as we grow, but our sense of self expands so that we can see different parts of our self. For example, you might be able to see that how you do in school (your academic self) is not quite the same as how you get along with others (your social self) or how you look (your physical self). So, when researchers study how people think about themselves, they often ask them specific things from each of those three parts of the self. 
Figure 2

Thinking about others and the self. The MPFC (green) is active when people of all ages think about others (left thought bubble), but for teens, it is also active when they think about themselves (right thought bubble). For children, the MPFC is not active when thinking about themselves. For adults, the $\mathrm{MPFC}$ is somewhat active when thinking about themselves, but not as much as for teens. Figure created using BioRender.com.

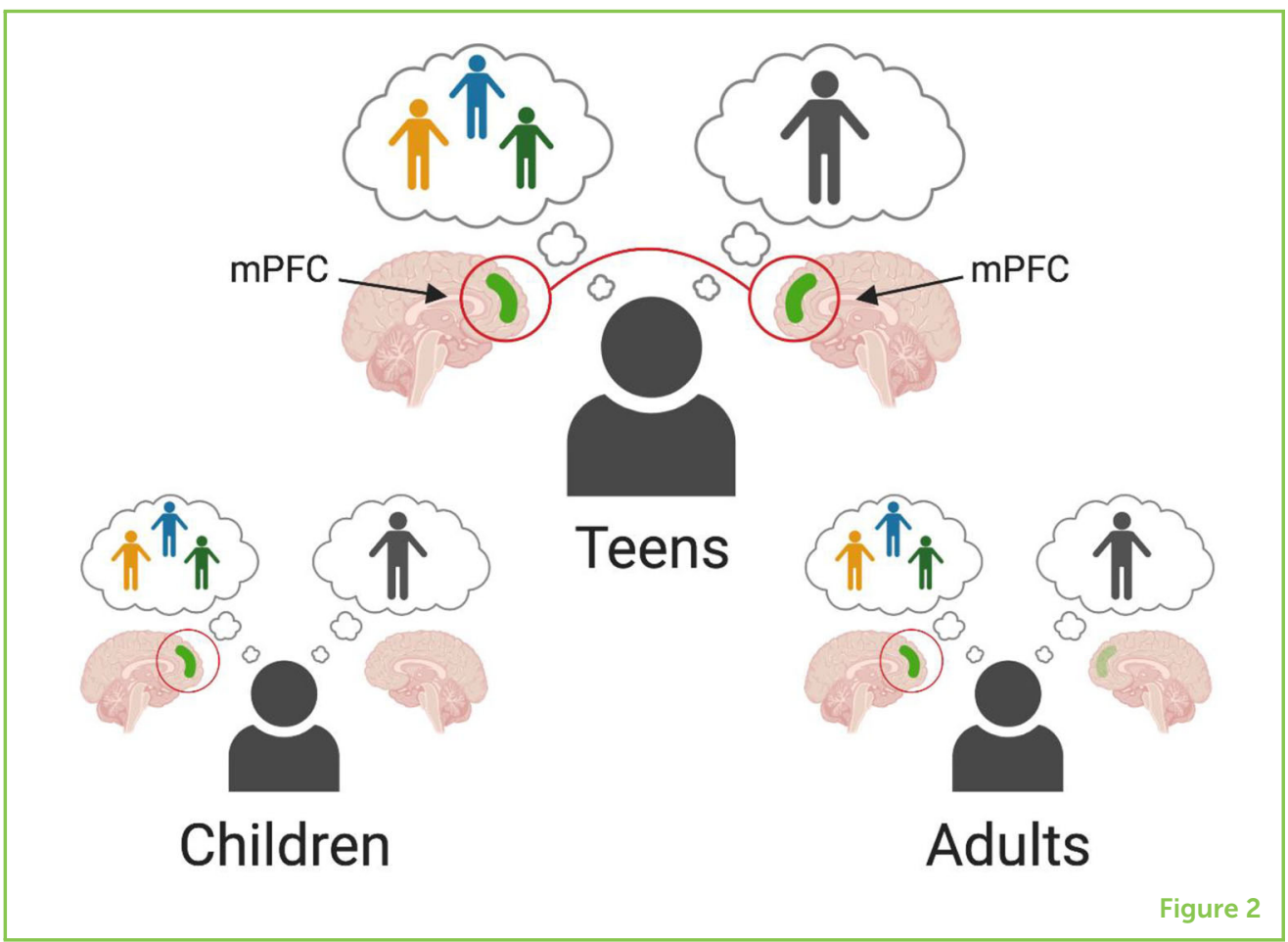

For example, people think about the academic self by seeing statements on a screen, such as "I am smart" and then pressing a button to agree or disagree. The social self will include statements like, "I have lots of friends," and the physical self will include things like, "I am pretty." Of those three parts of the self-academic, social, and physical, it makes sense that the social self would be the most social. Or, in other words, thinking about your social self is most likely to lead you to think about other people, too. Not surprisingly, the mPFC is the part of the brain that is most active when people think about their social selves!

\section{HOW DOES THE BRAIN CHANGE OVER TIME?}

But not everyone's MPFC is more active when thinking about the social self. One study examined children when they were age 10, and then had the same kids come back 3 years later when they were 13 . These are some really important ages, since lots of kids start going through puberty around then. The study found that as kids become teenagers, especially as their bodies start changing with puberty, the MPFC is more active when thinking about the social self [3]. Another study found that even though the MPFC becomes more active in the teenage years, its activity then decreases, and it is not as active in adulthood [4]. So, knowing what goes on in the brain has helped explain why our self-perceptions are most social during adolescence (Figure 2).

One other study found that it is not just the social self that gets more social as we grow, but also the physical self [5]. These researchers 
found that the MPFC is also very active when people think about their physical selves. And just like the social self, it keeps getting more active into the teenage years, until about age 15. After age 15, the mPFC starts being less active into adulthood. This means that around age 15, when we think about our physical selves, we also think about other people. Remember, thinking about others often means we are doing one of two things - comparing ourselves to others ("My physical self looks better/worse than his/hers") or wondering what others are thinking about us ("What do other people think about the way I look?"). So, this research finding shows that our brains are thinking more and more about others when we think about our physical selves during the teenage years.

\section{THE DEVELOPING BRAIN HELPS YOU GROW UP}

Bringing it all together, scientists have known for a long time that teens tend to be more social than both children and adults. This means that they start to care more about how they compare to others and what other people think of them. More recently, neuroscientists have helped us learn about important changes in the brain that can help explain why teens are more social. Starting around the time of puberty, the mPFC, which is a part of the social brain, starts to become more active when people think about themselves. Some might wonder why our brains become more social over time-is it just a random change or does it help us as we grow? Here, it is important to remember that adolescence (including the growing brain) has an important evolutionary function -it helps us transition from childhood to adulthood. As our brains become more social, we understand how we relate to others and how we fit into society, which helps us be ready for adult decisions and relationships. Not only does this science teach us some really cool things about ourselves, but it also shows us one of the many ways that neuroscience has helped us better understand how people grow and experience the world!

\section{ACKNOWLEDGMENTS}

We would like to thank Jane N. Jorgensen for providing helpful feedback on earlier drafts of this paper. We would also like to thank Deep Structure Productions (www.deepstructure.com) for the image used in Figure 1A.

\section{REFERENCES}

1. Harter, S. 2012. The Construction of the Self: Developmental and Sociocultural Foundations. 2nd Edn. New York, NY: Guilford.

2. Hoyos, P., Kim, N., and Kastner, S. 2019. How is magnetic resonance imaging used to learn about the brain? Front. Young Minds 7:86. doi: 10.3389/frym.20 19.00086 
3. Pfeifer, J. H., Kahn, L. E., Merchant, J. S., Peake, S. J., Veroude, K., Masten, C. L., et al. 2013. Longitudinal changes in the neural bases of adolescent social self-evaluations: effects of age and pubertal development. J. Neurosci. 33:7415-9. doi: 10.1523/JNEUROSCI.4074-12.2013

4. Pfeifer, J. H., Lieberman, M. D., and Dapretto, M. 2007. "I know you are but what am I?!": Neural bases of self- and social knowledge retrieval in children and adults. J. Cogn. Neurosci. 19:1323-37. doi: 10.1162/jocn.2007.19.8.1323

5. van der Cruijsen, R., Peters, S., van der Aar, L. P. E., and Crone, E. A. 2018. The neural signature of self-concept development in adolescence: the role of domain and valence distinctions. Dev. Cogn. Neurosci. 30:1-12. doi: 10.1016/j. dcn.2017.11.005

SUBMITTED: 26 January 2020; ACCEPTED: 04 September 2020; PUBLISHED ONLINE: 02 November 2020.

EDITED BY: Gideon Paul Caplovitz, University of Nevada, Reno, United States

CITATION: Jorgensen NA and Telzer EH (2020) Who Does Your Brain Think You Are? The Science of Thinking About Yourself. Front. Young Minds 8:529762. doi: 10. 3389/frym.2020.529762

CONFLICT OF INTEREST: The authors declare that the research was conducted in the absence of any commercial or financial relationships that could be construed as a potential conflict of interest.

COPYRIGHT (c) 2020 Jorgensen and Telzer. This is an open-access article distributed under the terms of the Creative Commons Attribution License (CC BY). The use, distribution or reproduction in other forums is permitted, provided the original author(s) and the copyright owner(s) are credited and that the original publication in this journal is cited, in accordance with accepted academic practice. No use, distribution or reproduction is permitted which does not comply with these terms.

\section{YOUNG REVIEWER}

\section{BEN, AGE: 13}

I am in seventh grade. I want to be an astronomer for NASA and discover new exoplanets, maybe with alien life. I have a black belt in Tang Soo Do and am currently working toward my second degree black belt. I really love to snowboard, read, and play video games.

\section{AUTHORS}

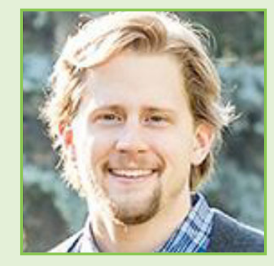

\section{NATHAN A. JORGENSEN}

I am a Ph.D. student in Psychology and Neuroscience at The University of North Carolina at Chapel Hill. My research aims to understand how we think about ourselves and other people. I am fascinated by how this changes throughout childhood and adolescence, especially how it is related to changes in the growing brain and the cultural environment that kids grow up in. *naj@live.unc.edu 


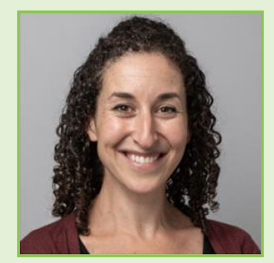

\section{EVA H. TELZER}

I am an Associate Professor of Psychology and Neuroscience at The University of North Carolina at Chapel Hill. My research uses several laboratory techniques to examine how social and cultural processes shape brain development. My research focuses on both antisocial (e.g., risk taking and substance use) and prosocial (e.g., helping and empathy) behaviors from childhood to adulthood, with a focus on adolescence as a particularly sensitive and flexible phase of brain development. 